\title{
More on nuclear winter
}

SIR - The intrinsic ambiguity of numerical simulations of atmosphere processes guarantees a protracted controversy about the phenomenon popularly called "nuclear winter", as for example described by Turco et $a l^{1}$.

There are, however, ways of injecting large masses of soot into the high atmosphere that are phenomenologically more explicit than those now described. It is necessary only to tell a systems programmer where one guesses the source of carbon should be and to ask him or her please to adjust the computer model accordingly. Consider targeting a coalfield.

The integration of biomass over geological time has endowed millions of square kilometres of the Earth's surface with fossil fuel loadings in the range from 100 to $10,000 \mathrm{~g} \mathrm{~cm}^{-2}$ (ref. 2), compared with the 1 to $50 \mathrm{~g} \mathrm{~cm}^{-2}$ that constitutes the carbon budget of the rural and urban fires in ref. 1. An unknown fraction of this ubiquitous coal, lignite, oil shale and peat is either exposed or lies beneath a thin veneer of overburden ${ }^{3}$, and is at risk of interaction with energetic phenomena, including thermonuclear surface bursts and cataclysmic volcanism.

Warheads with yields in excess of 0.5 megatons detonated in such carbonaceous terrain can promptly transform the ground beneath into a mixture of carbonaceous plasma and particulates launched towards the stratosphere by direct entrainment in the rising fireballs. Efficiencies of roughly 10 to 100 megatons of soot per gigaton exploded seem likely (J. Nuckolls and L. Wood, personal communication). It should be noted that NATO (North Atlantic Treaty Organisation) and Warsaw Pact missile fields and fossil fuel fields are partially coextensive, as are the loci of cataclysmic calderas and the massive (trillion ton) hydrocarbon resources that occupy $\geq 10$ per cent by area of the western United States.

Every few hundred thousand years, that region is host to a randomly located eruption of 250 to 2,500 cubic kilometres of incandescent tephra. Dr Turco has expressed his willingness to accept the largest of these events as analogues in their climatic impact to the dust baseline of ref. 1. In recent geological history, these eruptions have eviscerated about 5 per cent of the area in question. The worst-case scenarios arising from the interaction of caldera volcanism and fossil fuels involve both carbon and energy budgets that dwarf its inputs of nuclear winter. What were the consequences - local or global, mild or catastrophic?

A survey of the extent of their geological events and of their palaeoecological consequences might serve to illuminate the extent to which the nuclear winter model is a valid predictor of the fate of the Earth. Since a rough calculation yields a mean time of rather less than 10 million years between events capable of producing catastrophic natural carbon injections, the fact that we are not extinct may be germane to the present controversy.

It remains to be seen whether the neologism "nuclear winter" will ever qualify as what philosophers of language call a "rigid designator in the real set", two examples of which are "Carbon County, Wyoming" and "The Yellowstone Caldera". I do not mean to consign "the nuclear winter" to the null set, exemplified by "the canals of Mars" and "the unicorn", but merely wish to point out that a fossil rhinoceros in the hand is more amenable to analysis than two unicorns in the software, and that a diligent search of the fossil record has turned up many a rough beast in the past.

RusSEll SEITZ American Security Council Foundation, Boston, Virginia, USA

1. Turco, O.R., Toon, P. B., Ackerman, T.P., Pollack, T.P. \& Sagan, C. Science 222, (1983).

2. Seitz, R. Reflections on Nucleur Winter in Proceedings of the 4 ih International Seminar on Nuclear War: Nuclear Winter and the New Defense Systemts, Problents and Perspectives, Erice, 19-29 August 1984. Reidel, in preparation.

. Department of the Intcrior, Synfuels Resources (Washington, 19831.

\section{Nullius in verba}

SiR - In your reference to the motto of the Royal Society (Nature 2 May, p.9) you make two mistakes. First you misquote the motto itself, and then you give a totally false translation.

The motto is Nullius in verba, the word nullius being the genitive whereas you give nullus, the nominative.

Admittedly, the meaning of the motto is obscure until one knows the rest of the line of Horace (Epistolae, I, i, line 14) from which the words are taken. This reads: Nullius addictus jurare in verba magistri, which may be translated as "Not committed to swearing by the words of any master'. Here Horace declares to his patron Maecenas his own attitude to authority, and it is this rejection of authority as a source of truth that the Royal Society expresses in its motto. Your translation, "nothing in words", is wide of the mark.

ANDREW HUXLEY

The Royal Society,

6 Carlton House Terrace,

London SWIY $5 A G, U K$

\section{Mass extinctions}

SiR - Coming when it did, Michael Benton's article in News and Views (Nature 11 April, p.496) must have appeared like manna from heaven to the hundreds of geology and zoology undergraduates throughout the country, and presumably at his institution too, preparing for their final examinations this summer.
It is therefore important to note that Benton chose not to include the single most parsimonious hypothesis underlying the phenomenon of mass extinctions, namely that extinction events are the result of any number of external but unrelated causes which, as a result of simple probability, appear to occur with regularity.

Whether he likes it or not, this single hypothesis, concerned as it is with historic events, will perpetually thwart any attempts to falsify it. The demonstration of cyclicity paralleling these events does not establish a cause/effect relationship. The isolation of a likely cause in one or two cases cannot be extrapolated to the whole. Similarly, the prediction of the cause of the next is not going to help the debate now.

We are left with five explanations for mass extinction cycles. Arguments for and against each view, though futile, will continue. More detailed analyses of the fossil data, and refinements in dating events in the geological past, will not help us to decide which view is correct, though they may enable us to say which is most likely.

GRAHAM B. WILSON

Department of Anatomy \& Biology

as Applied to Science,

Middlesex Hospital Medical School, London WIP $6 D B, U K$

\section{Future of RGO}

SIR - Philip Campbell commented in Nature (28 March, p.303) that the staffs of the Royal Greenwich Observatory (RGO) and the Royal Observatory Edinburgh would greet with weary shrugs of resignation the news that the Science and Engineering Research Council (SERC) is to set up yet another committee to decide their future.

Dr Campbell is right in the sense that we have been subjected to so many of these exercises, this will be the fourth since 1983 , that much time which should have been spent on observatory projects has been dissipated in justifying our existence.

The staff of this observatory are certainly not, however, facing SERC's latest investigation in a spirit of resignation. On the contrary, we believe that what we have achieved and are continuing to achieve in spite of under-funding and uncertainty is proof that $\mathrm{RGO}$ is a viable and efficient base for the support of astronomical research for the United Kingdom and its international partners.

Moreover, the scientific damage likely to be caused by any major disruptions at this stage when we are completing the new observatory on La Palma is too serious to contemplate with anything approaching resignation. The staff at $\mathrm{RGO}$ will be entering into discussions on the situation with vigour and determination.

Acting Chairman, RGO Staff Side Royal Greenwich Observatory, Herstmonceux Castle,

Hailsham, East Sussex BN27 IRP, UK 